\title{
The Assurance Of Learning Process Components And The Effects Of Engaging Students In The Learning
}

\author{
Joseph B. Mosca, Ed.D, Monmouth University, USA \\ Gilder Agacer, CPA, Ph,D, Monmouth University, USA \\ Linda Flaming, CPA, Ph.D., Monmouth University, USA \\ John Buzza, MBA, Monmouth University, USA
}

\begin{abstract}
Assurance of learning process plays a major role in higher education and has increased the accountability on the part of instructors at all levels. This paper will discuss the role of assurance processes in teaching and the ways to measure these processes of student learning. The research focus will be to determine if student engagement in problem solving and hands on experiences during the learning assist the learning process?
\end{abstract}

\section{INSTRUCTION AND THE ZONE OF PROXIMAL DEVELOPMENT}

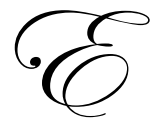

mpirical and theoretical learning illustrates Vygotsky's (1986), belief that well designed instruction is as if the instructions were a magnet. How this magnet works is if the instructor designs the lesson slightly ahead of what the students know at the present time, the material currently being presented along with the currently known knowledge will magnetize bringing the students to the next level. This process is also linked to scaffolding that is a technique supporting student learning. Simply put, helping students answer difficult questions or solve problems by giving them hints or asking leading questions is an example of scaffolding (Gallimore \& Tharp, 1990, Ratner, 1991).

The role of assurance learning processes in teaching:

Many business school instructors attempt to develop their students' understanding of business. According to Durden (2008), there is actually a degree of confusion and uncertainty about what "developing understanding" really means. Therefore a number of negative consequences for teachers and students remain to be explored. He introduces "Constructive Alignment" a teaching approach to designing courses which show consistency between learning objectives, teaching and learning activities, and assurance of learning. Therefore, learning objectives are put forth in the form of different levels of understanding, while the instructor chooses teaching techniques that develop those different levels. Then assurance of learning focuses on the objectives to see if what the objectives state the students should have learned is what they actually learned (Cohen, 1987).

\section{There are six key elements in the assurance learning process:}

1- $\quad$ Measurement: assigning numbers or ratings according to rules to create a ranking.

2- $\quad$ Evaluation: making judgments about the value of a measure.

3- $\quad$ Summative evaluation: measure achievement, and then assign grades.

4- $\quad$ Formative evaluation: monitor progress, plan remedial instruction.

5- $\quad$ Tests can positively affect many aspects of students' learning.

6- $\quad$ Moderate testing produces more learning than no testing or infrequent testing.

The above six assurance elements indicate that classroom assurance of learning processes do provide several purposes such as, they highlight information about the extent to which students have acquired the knowledge and skills that have been recently taught and: 
- Indicate whether or not the students understand what is being taught?

- $\quad$ Are the students abreast with the pace at which the lessons are taught?

- $\quad$ Are particular causes of student learning difficulties identifiable?

- Is there any indication that students can effectively regulate their study efforts?

Using Bloom's Taxonomy when devising teaching objectives and assurance of learning processes is a classic approach and here is a breakdown of this approach:
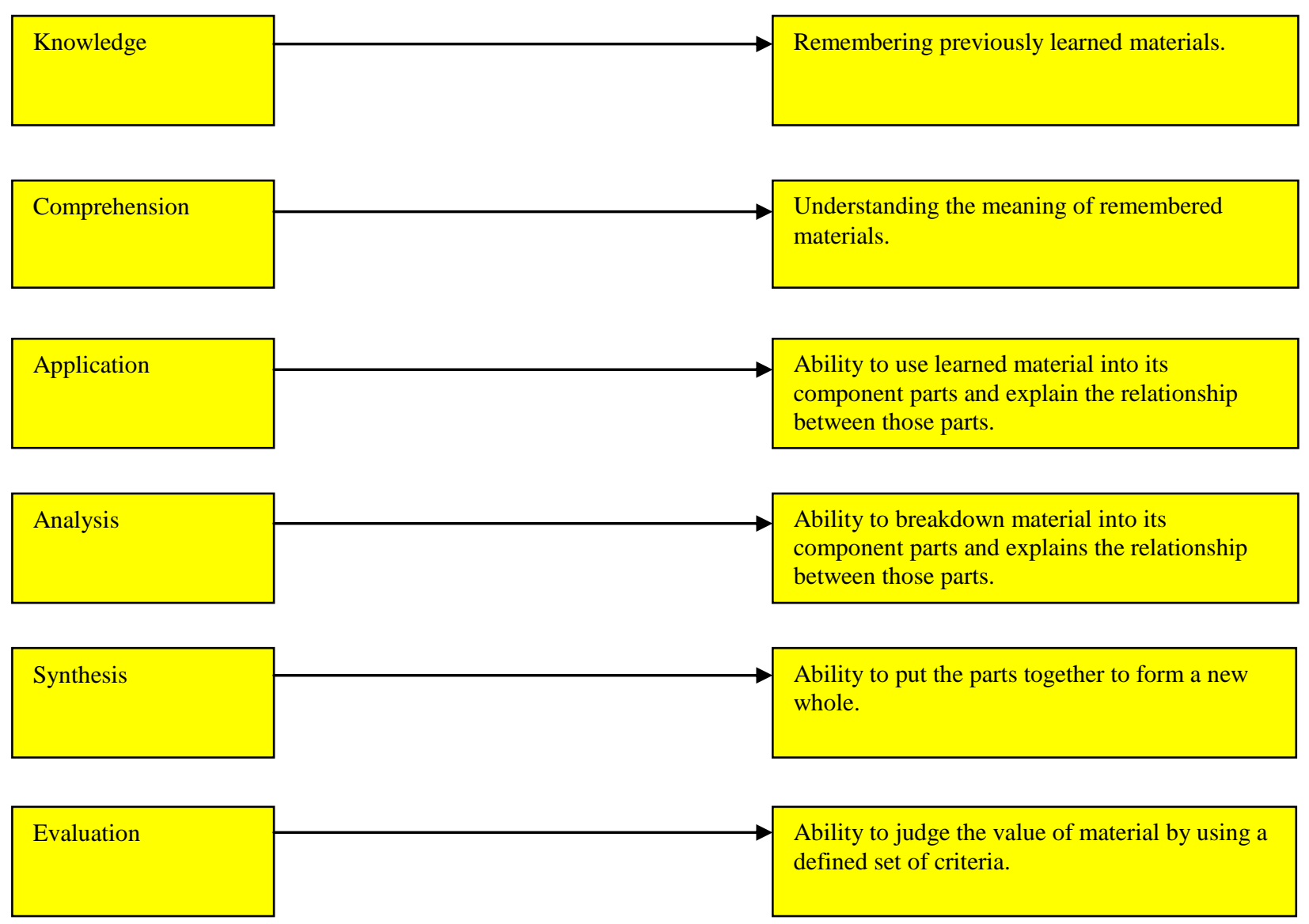

Now is the time to consider how do students learn? The memory has four systems which are: The Declarative memory which handles recall of information. The Non-declarative is a portion of the memory which handles the recall of actions. The Semantic versus episodic system that contains general knowledge that is not temporally dated and the episodic system is another portion of the memory system which handles recollections of personal experiences. The Prospective versus retrospective is the system that involves remembering to perform actions of the future, and the retrospective memory involves remembering events from the past (Weiten, 2011).

According to Bently (2009), the concept of students having the ability to assess their own work could be a key factor of assessment of learning. He sites Williams (1998), as stating that self-assessment should not be overlooked and considered a luxury, for self-assessment is in fact an essential part of formative assessment. Here are three benefits of students who were taught how to assess their own work:

- When a student gets to a point whereby he or she can accurately evaluate the quality of their own work, which in turn can build their own confidence. 
- $\quad$ Because of self-confidence and being able to accurately evaluate their own quality of work, a majority of students will perform better on homework assignments and achieve higher grades.

- $\quad$ With the gained ability of quality self-evaluations and better performance on homework and higher all around grades, teachers will spend less time assessing and more time sharing knowledge with students.

Wilson (2010), introduces the "Enterprise Capability," concept as:

...the capability to handle uncertainty and respond positively to change, to create and implement new ideas and new ways of doing things, to make reasonable risky-reward assessments and act upon them in one's personal and working life. This depends on the development of knowledge and understanding of concepts, skills, and attitudes.

So then why should we assess enterprise capability? DFES by NFER published in Assessing Enterprise Capability: Guidance for Schools, NFER (2007), if students develop their enterprise capability more successfully, then effective assessment can be in-place. Then the question presents itself as, how can enterprise capability be assessed and what are the components?

$\begin{array}{ll}\text { - } & \text { Problem solving } \\ \text { - } & \text { Risk management } \\ \text { - } & \text { Creativity } \\ \text { - } & \text { Communication and presentation skills } \\ \text { - } & \text { Teamwork } \\ \text { - } & \text { Decision-making } \\ \text { - } & \text { Innovation } \\ \text { - } & \text { A can-do attitude }\end{array}$

These nine components should lead to students being able to identify a problem and then generate ideas from the problem, be capable of planning a solution for the problem, be capable of implementing the plan, the evaluating the process, for example take note of the following model:

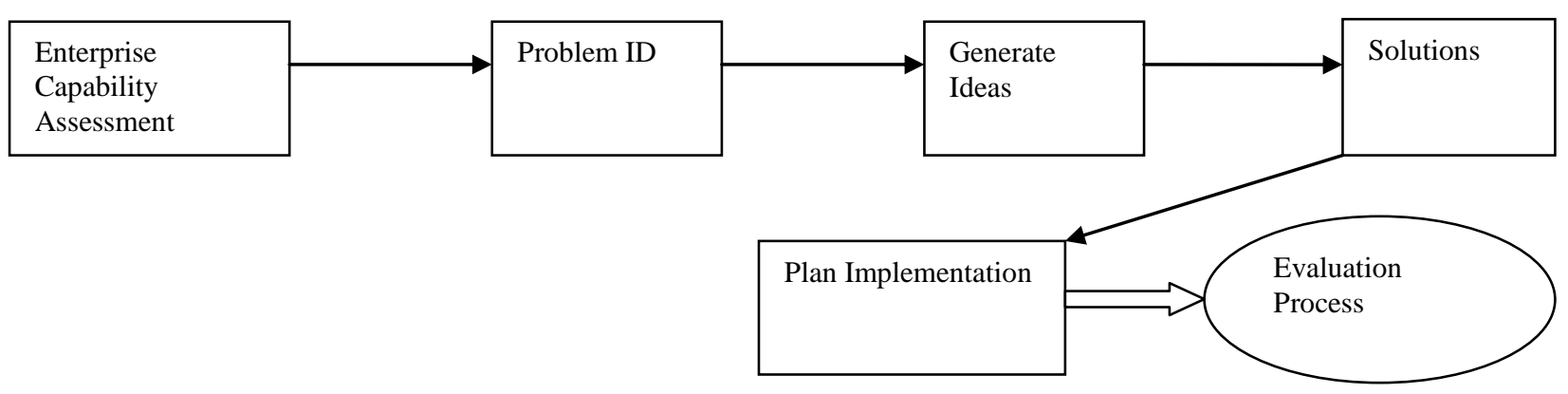

Barnes (2009), claims that the question is the answer, for he asks: "How could we ask questions that strikes a chill in the heart of education?" What needs to be considered is that the subject belongs t the teacher, the lesson belongs to the teacher, as with the topic, text book, and work assigned. So then what do teachers have to rely on for teaching to take place and then to assess? One component is the relationship among the students and the teacher and if the proper environment is set whereby students are confident, questioning can begin. Now questioning alone is not the fix for assessment the environment needs to be established by the teacher so that the question is asked, how does this correlate with theory and practice, and then reflect on the question. The authors are suggesting the following teaching essentials be put into action prior to assessment. 
- Helping students learn is the teacher's job, and we must ask ourselves the following questions:

- $\quad$ Do we provide verbal examples?

- Do we demonstrate action?

- Do we provide practice time?

- $\quad$ Do we guide the practice time?

- $\quad$ How do we provide feedback?

- $\quad$ Do we teach for the future?

- Does your lesson plan relate to the students' levels?

- Do we assume that all students are interested in the subjects we teach?

- $\quad$ Do we assume that all students' know what we are talking about?

- $\quad$ Are we always maintaining students' attention?

- $\quad$ Do you really think that you can lecture for the entire class period?

Barrie, Ginns, and Prosser, (2005), seem to agree with the authors, for they believe that in order to improve students' learning outcomes, teachers need to be concerned about both context and how the students' experience toe context. If a school is to establish policies and practices for the assurance of learning processes, it would be expected to have substantial effects on the way faculty approach their teaching and structure the teaching and learning process, it is imperative these practices and policies must have the students' in mind. With that said the authors further suggest that the following be kept in mind by all teachers must ask themselves:

- $\quad$ Are students' natural learners? (NO).

- $\quad$ Students of all ages are relatively naïve about how they can best learn something.

- $\quad$ Most students use ineffective strategies when they study.

- Most students do not elaborate on classroom material.

- What are some of the reasons why your students may not want to learn your subject matter? The answer may be one or any of the following common mistakes:

1- Lesson plans do not utilize the building block approach.

2- You assumed that students' study.

3- You have not built a trust relationship within the classroom environment.

4- All you students' do not get an opportunity to interact during class time.

5- Do you interact with your students?

Teaching and learning have been brought to light and now collaborative learning is defined by Sandahl (2009), simply put is students working together to learn. Collaborative learning strategies are both active and student centered as the authors mentioned above. These intellectual activities usually involve groups of students engaged in discussions, peer teaching activities, group case studies, study groups, research teams, and peer assessment. On the one hand the goal of the collaborative learning concept could be the completion of a specific task that could be a group test or presentation. On the other hand the collaborative strategy may be the process itself, where students reflect on the group process and what could be done to improve it. Research indicates that a variety of collaborative learning strategies have been used successfully to promote achievement of knowledge and skills at all grade levels and in multiple subject. There are three theoretical frameworks to support collaborative learning strategies, which are:

1- $\quad$ Cognitive development, which points out that social interaction, is necessary for human development.

2- Behavioral learning, which supports that learning, is social and brings into play rewards and punishments, for students will model behavior if they perceive benefit or a reward.

3- $\quad$ Social interdependence indicates that it is a way the task is structured that determines the outcomes. In positive interdependence students' will support each other, indicating that students are motivated to work as a group to achieve a goal.

Lavy and Yadin (2010), conducted a study designed to enhance student's capabilities to comprehend nontechnical knowledge in critical thinking, team skills, an understanding of business. The focus and objective of the study was to examine the effects of team based peer review on the students' learning process. The findings 
indicated when students take on the role as evaluators of others it exposes them to ideas that vary from their own which in turn allowed them to rethink their approach to problem solutions, in turn the students evaluating others were prompted to and motivated to search for better and efficient ideas, This one study indicates that when students share the assessment process the level of understanding is greater.

Fairbrother and Barros,(2010), examined the effects of interference and repeated retention tests as a form of learning assessment. The test comprised of pressing five keys. The results of this repeated test study highlight three important implications. 1- The findings reinforce the evidence that retention testing is not a neutral event, therefore, consideration should be given to using repeated testing in experimental designs. To date there is no current knowledge that offers anything more than vague advice to except for "handle with care," for there is no clear understanding of the factors to consider when deciding whether repeated testing is advantageous. 2- Researchers need to be Aware of the potential impact repeated retention procedures might have on interpreting results. 3Retention testing may offer a viable technique to enhance motor skills learning.

Harmer, Brian, (2009). Conducted a study that should be helpful for instructors, for they need to keep in mind when considering assurance of learning and take into account students experiences. Their study revealed that there was general agreement among participants that students conditioned by prior workplace experience are generally better equipped to make sense of the concepts covered in business courses. Some suggested that, even if the prior workplace exposure were in a different domain to the subject matter taught in the course, the students would be better able to associate with the concepts being taught.

\section{Why Instructors at all Levels Need to Employ Sound Teaching Methods for Learning Assurance.}

According to Ravitch (2010), accountability is becoming a hoax. Her findings indicate there is continuing evidence that indicates our current accountability policies are a great fraud and hoax, however our elected officials and policymakers remain completely oblivious to the harm caused by policies they mandate. It has become vogue over the past few years for politicians and administrators to put efforts to hold teachers and schools accountable. These efforts of accountability have resulted into perverse consequences, instead of better education. The results have been cheating scandals, teaching to bad tests, narrow curriculum, lowered standards, and gaming of the system. Ravitch points out that all of these accountability efforts may produce higher test scores (of dubious validity), but high stakes accountability does not produce better education, or for that matter, better teaching methods.

\section{RESEARCH METHOD}

An assurance of learning survey will be distributed to undergraduate and graduate students who will respond to 6 questions, using the Agree, Strongly Agree, Disagree, Strongly Disagree, N/A scale. The survey does not require the instructors and students names to be listed, only the name of the course is required to separate graduate from undergraduate.

Hypothesis 1: When students are engaged in problem solving and hands on experiences, comprehension of concepts are easier.

Hypothesis 2: When students are engaged in the learning process they are able to explain what they learned and apply it.

Hypothesis 3: The can apply what they have learned outside the classroom.

Hypothesis 4: Students will agree that when engaged in the learning process through problem solving and or hands on experiences, they can better retain concepts. 


\section{ASSURANCE OF LEARNING SURVEY SAMPLE:}

\section{Name of Course}

Please complete the following questions to assist us with a study to measure how effective your knowledge of the subject matter you were engaged in, and how helpful the knowledge has been to you. It is not required that you put your name or the instructors.

1- Would you agree that you had some problem solving or hands on experiences in this class?

__Agree, ___Strongly Agree, __ Disagree, ___ Strongly Disagree, ___N/A

2- $\quad$ Do you understand the meaning of the material you engaged in, such as: I learned that management is getting things done through people.

__ Agree, __ Strongly Agree, ___ Disagree, __ Strongly Disagree, __ N/A

3- $\quad$ Are you able to explain what you learned and how it relates to other concepts, such as: A Dean is a manager because she/he gets courses taught by professors.

__Agree, ___ Strongly Agree, __ Disagree, __ Strongly Disagree, ___N/A

4- Can you relate what you have learned outside the classroom?

___Agree, __ Strongly Agree, ___ Disagree, ___ Strongly Disagree, __ N/A

5- $\quad$ Can you agree that you have benefited from group experiences or problem solving.

__Agree, ___Strongly Agree, ___ Disagree, ___ Strongly Disagree, __

6- Would you agree that the hands on experiences or problem solving will help you retain the material content of this class?

__Agree, ___Strongly Agree, ___ Disagree, __ Strongly Disagree, __ N/A

\section{FINDINGS}

A total of 200 surveys were distributed to undergraduate and graduate students of which $49 \%$ were female, $51 \%$ male, and $26 \%$ were graduate students, 189 responded responding to the questions based on the methods of teaching in the class they were currently in, as indicated below:

- $\quad$ Overall $87 \%$ of the survey respondents agreed or strongly agreed that they had some problem solving or hands on experience in their current class.

- $\quad$ Nearly all respondents (99.47\%), indicated that the meaning of the material and concepts being taught with the use of problem solving and or hands on experiences were understood.

- $\quad$ An overwhelming $97.88 \%$ responded that they are able to explain what they learned and how what they learned related to other concepts.

- $\quad$ All of the respondents $(100 \%)$, indicated that when learning concepts through the use of problem solving and or hands on experiences, they are able to relate the concepts outside the classroom.

- When respondents were asked if they benefited from problem solving within a group setting, 98.94 agreed they benefited from group experiences of problem solving.

- $\quad$ Generally $98.41 \%$ agreed that the hands on experiences and or problem solving have helped them retain material and concepts presented to them in the class being surveyed. 


\section{ASSURANCE OF LEARNING SURVEY}

Overall, the results of the Assurance of Learning Survey overwhelmingly skew in favor of agreement. The majority of responses - or, $91.82 \%$ (1571 of 1638) - 'agreed' or 'strongly agreed' with the question stems as presented. As seen below, only two responses were tallied for 'not applicable' and two 'non-responses' were tallied (both of the latter occurring on question number ten). The total number of responses, broken down by question, is then as follows:

\begin{tabular}{|cc|}
\hline Question \# & Total Responses \\
\hline 1 & 189 \\
\hline 2 & 189 \\
\hline 3 & 189 \\
\hline 4 & 189 \\
\hline 5 & 189 \\
\hline 6 & 189 \\
\hline 7 & 127 \\
\hline 8 & 127 \\
\hline 9 & 127 \\
\hline 10 & 125 \\
\hline
\end{tabular}

Individual responses as tallied, by type of response and question number:

\begin{tabular}{|cccccc|}
\hline Question \# & Agree & Strongly Agree & Disagree & Strongly Disagree & N/A \\
\hline 1 & 71 & 93 & 25 & 0 & 0 \\
\hline 2 & 69 & 119 & 1 & 1 & 0 \\
\hline 3 & 92 & 93 & 3 & 0 & 0 \\
\hline 4 & 71 & 118 & 2 & 0 & 0 \\
\hline 5 & 78 & 109 & 3 & 0 & 0 \\
\hline 6 & 55 & 131 & 12 & 6 & 1 \\
\hline 7 & 69 & 38 & 3 & 0 & 0 \\
\hline 8 & 71 & 46 & 2 & 0 & 0 \\
\hline 9 & 53 & 72 & 2 & & 0 \\
\hline 10 & 41 & 82 & & & 0 \\
\hline
\end{tabular}

Given the totals and tallies, response percentages were then calculated as follows (at a minimum of three significant digits):

\begin{tabular}{|cccccc|}
\hline Question \# & Agree & Strongly Agree & Disagree & Strongly Disagree & N/A \\
\hline 1 & $37.57 \%$ & $49.21 \%$ & $13.23 \%$ & $0.00 \%$ & $0.00 \%$ \\
\hline 2 & $36.51 \%$ & $62.96 \%$ & $0.53 \%$ & $0.00 \%$ & $0.00 \%$ \\
\hline 3 & $48.68 \%$ & $49.21 \%$ & $1.59 \%$ & $0.53 \%$ & $0.00 \%$ \\
\hline 4 & $37.57 \%$ & $62.43 \%$ & $0.00 \%$ & $0.00 \%$ & $0.00 \%$ \\
\hline 5 & $41.27 \%$ & $57.67 \%$ & $1.06 \%$ & $0.00 \%$ & $0.00 \%$ \\
\hline 6 & $29.10 \%$ & $69.31 \%$ & $1.59 \%$ & $0.00 \%$ & $0.00 \%$ \\
\hline 7 & $54.33 \%$ & $29.92 \%$ & $9.45 \%$ & $5.51 \%$ & $0.79 \%$ \\
\hline 8 & $55.91 \%$ & $36.22 \%$ & $2.36 \%$ & $4.72 \%$ & $0.79 \%$ \\
\hline 9 & $41.73 \%$ & $56.69 \%$ & $1.57 \%$ & $0.00 \%$ & $0.00 \%$ \\
\hline 10 & $32.80 \%$ & $65.60 \%$ & $1.60 \%$ & $0.00 \%$ & $0.00 \%$ \\
\hline
\end{tabular}


Generally rounded to the ones place:

\begin{tabular}{|cccccc|}
\hline Question \# & Agree & Strongly Agree & Disagree & Strongly Disagree & N/A \\
\hline 1 & $38 \%$ & $49 \%$ & $13 \%$ & $0 \%$ & $0 \%$ \\
\hline 2 & $37 \%$ & $63 \%$ & $1 \%$ & $0 \%$ & $0 \%$ \\
\hline 3 & $49 \%$ & $49 \%$ & $2 \%$ & $0 \%$ & $0 \%$ \\
\hline 4 & $38 \%$ & $62 \%$ & $0 \%$ & $0 \%$ & $0 \%$ \\
\hline 5 & $41 \%$ & $58 \%$ & $1 \%$ & $0 \%$ & $0 \%$ \\
\hline 6 & $29 \%$ & $69 \%$ & $2 \%$ & $6 \%$ & $1 \%$ \\
\hline 7 & $54 \%$ & $30 \%$ & $2 \%$ & $5 \%$ & $0 \%$ \\
\hline 9 & $56 \%$ & $36 \%$ & $2 \%$ & $0 \%$ & $0 \%$ \\
\hline
\end{tabular}

\section{Graphical depictions:}
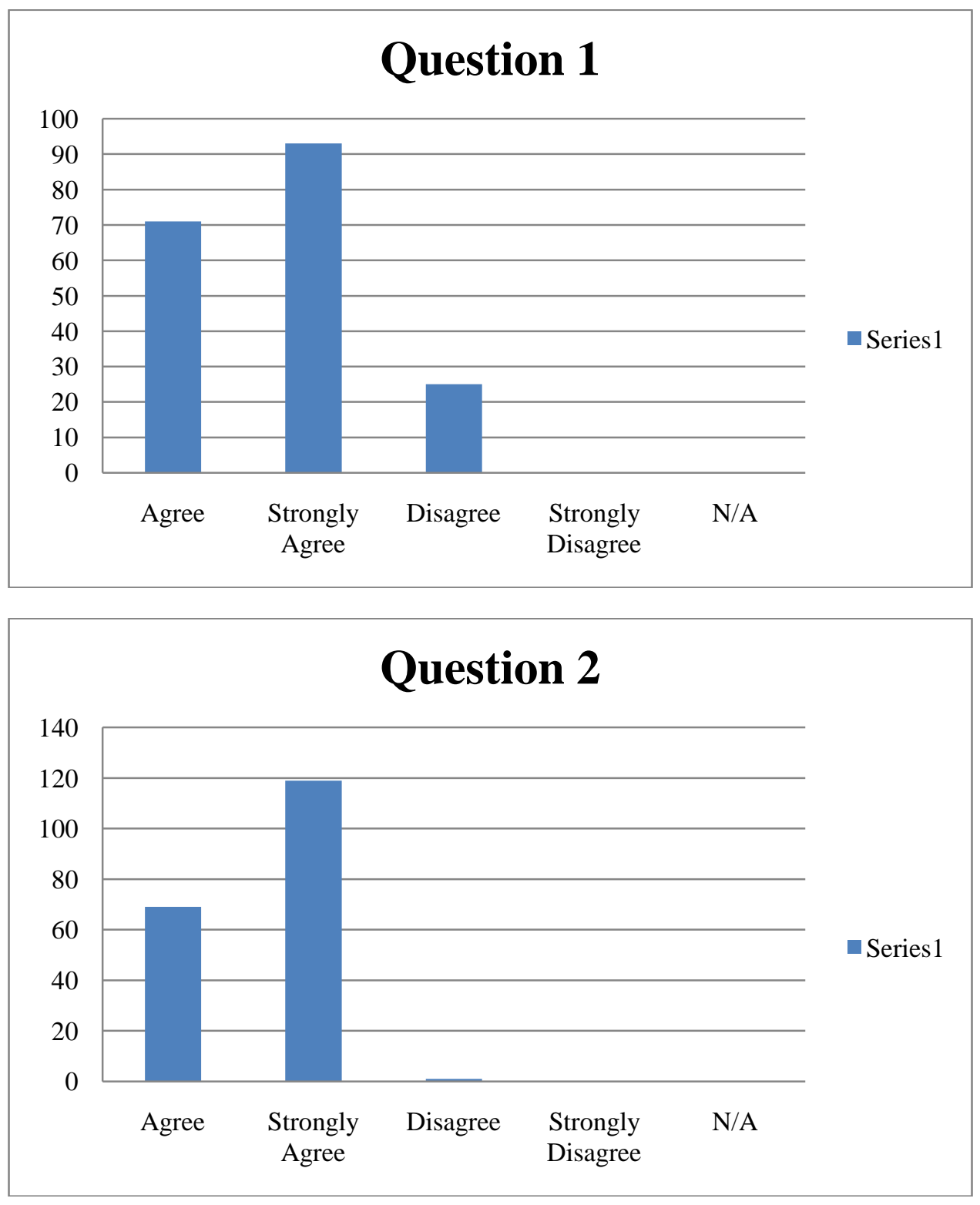

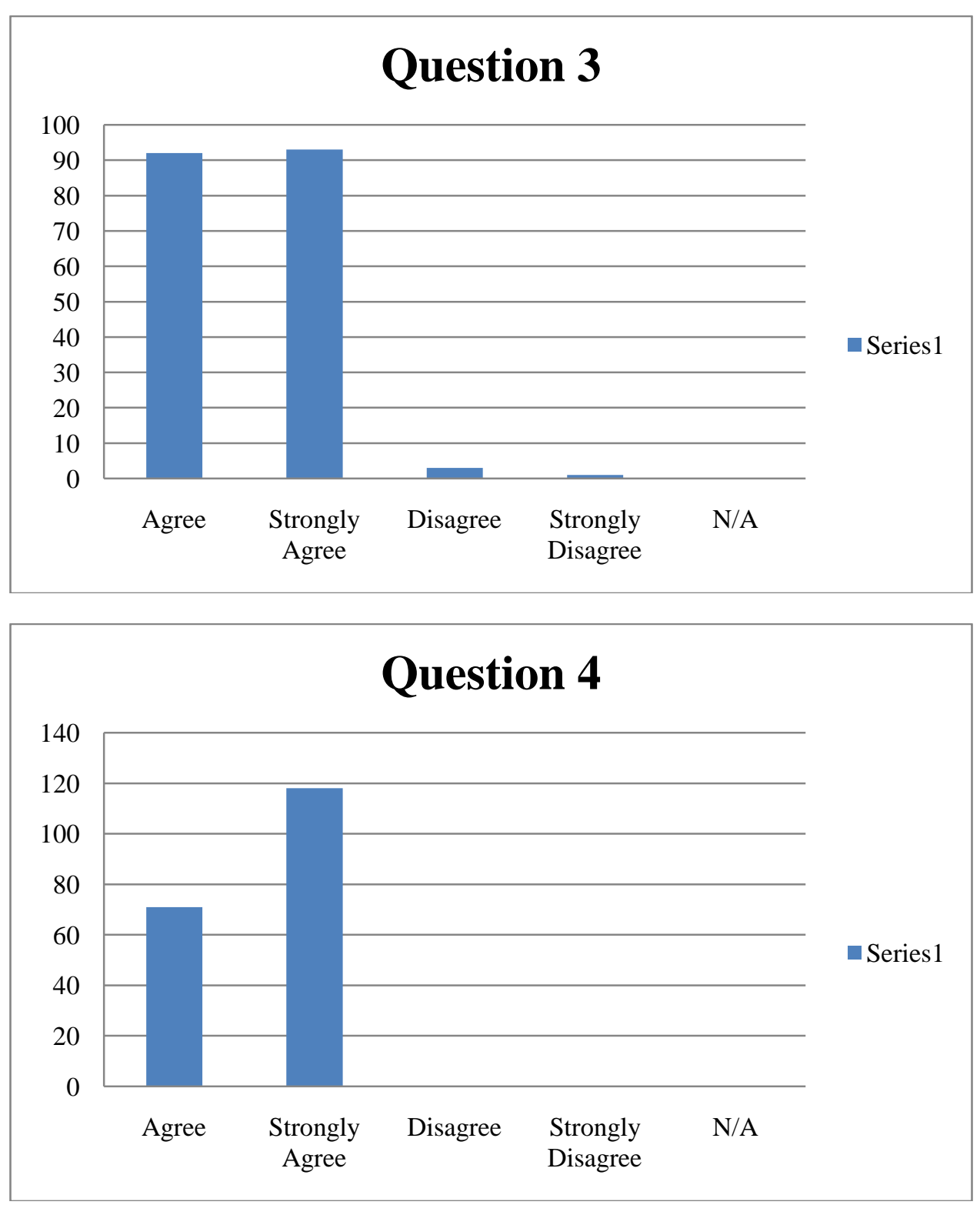

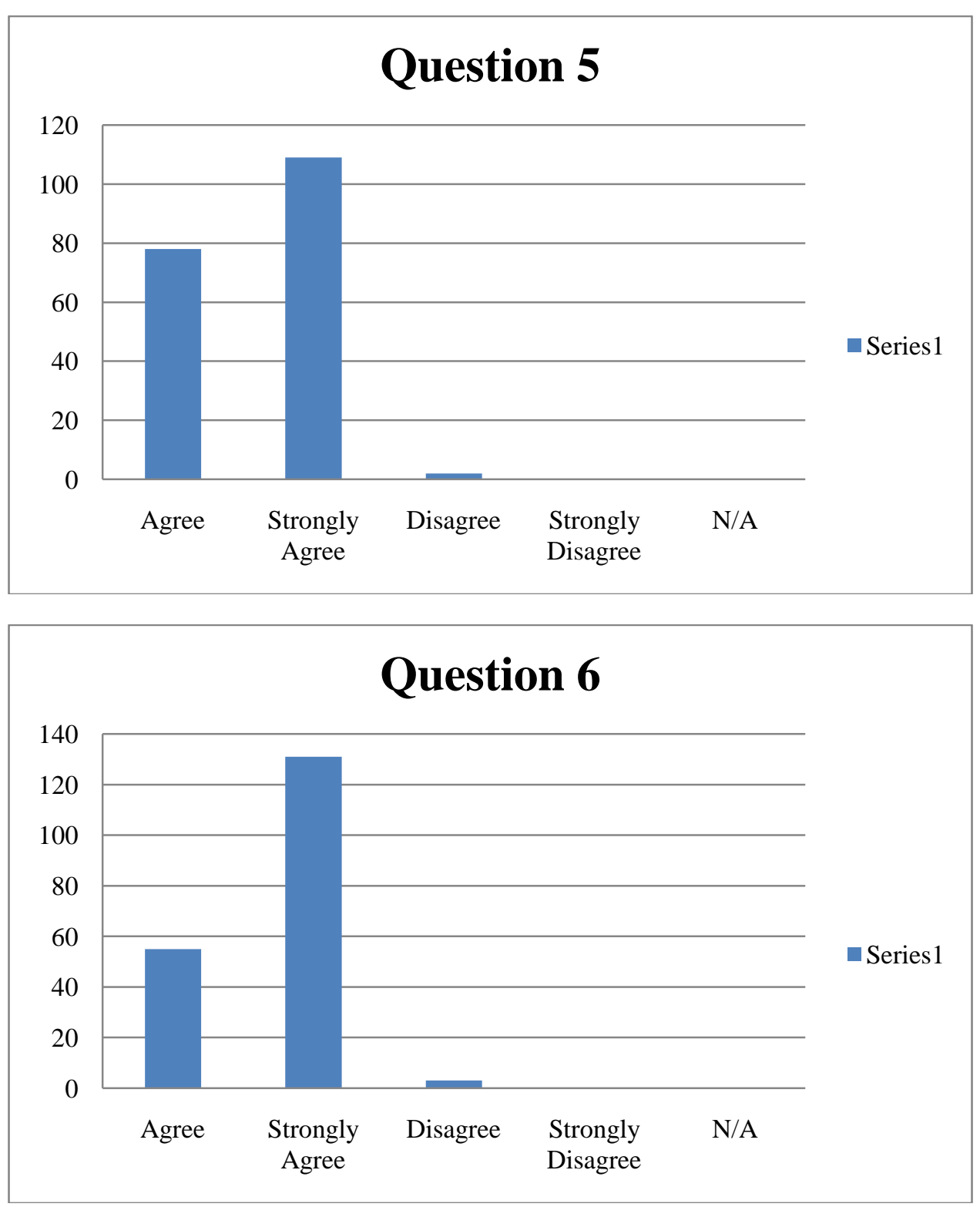

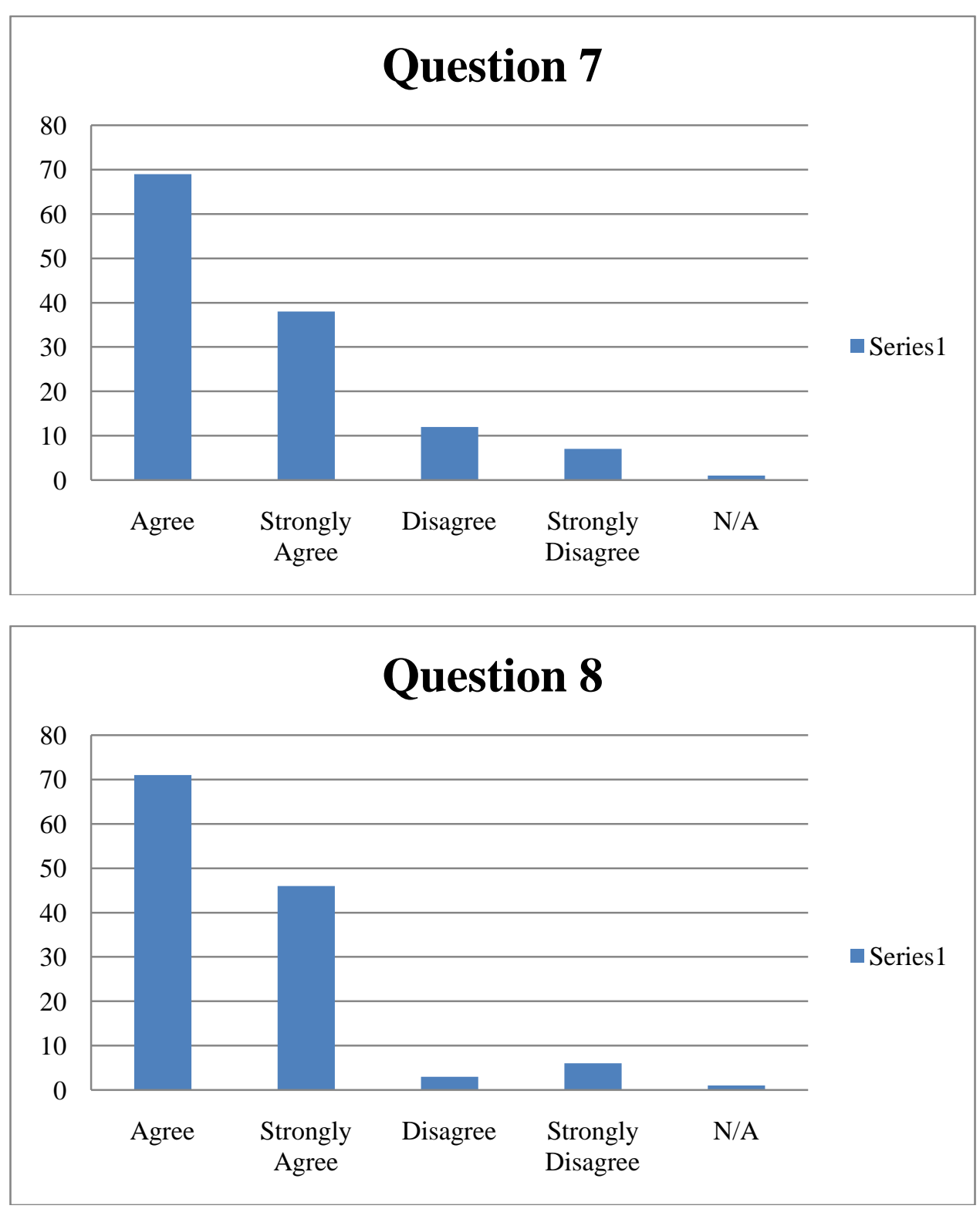

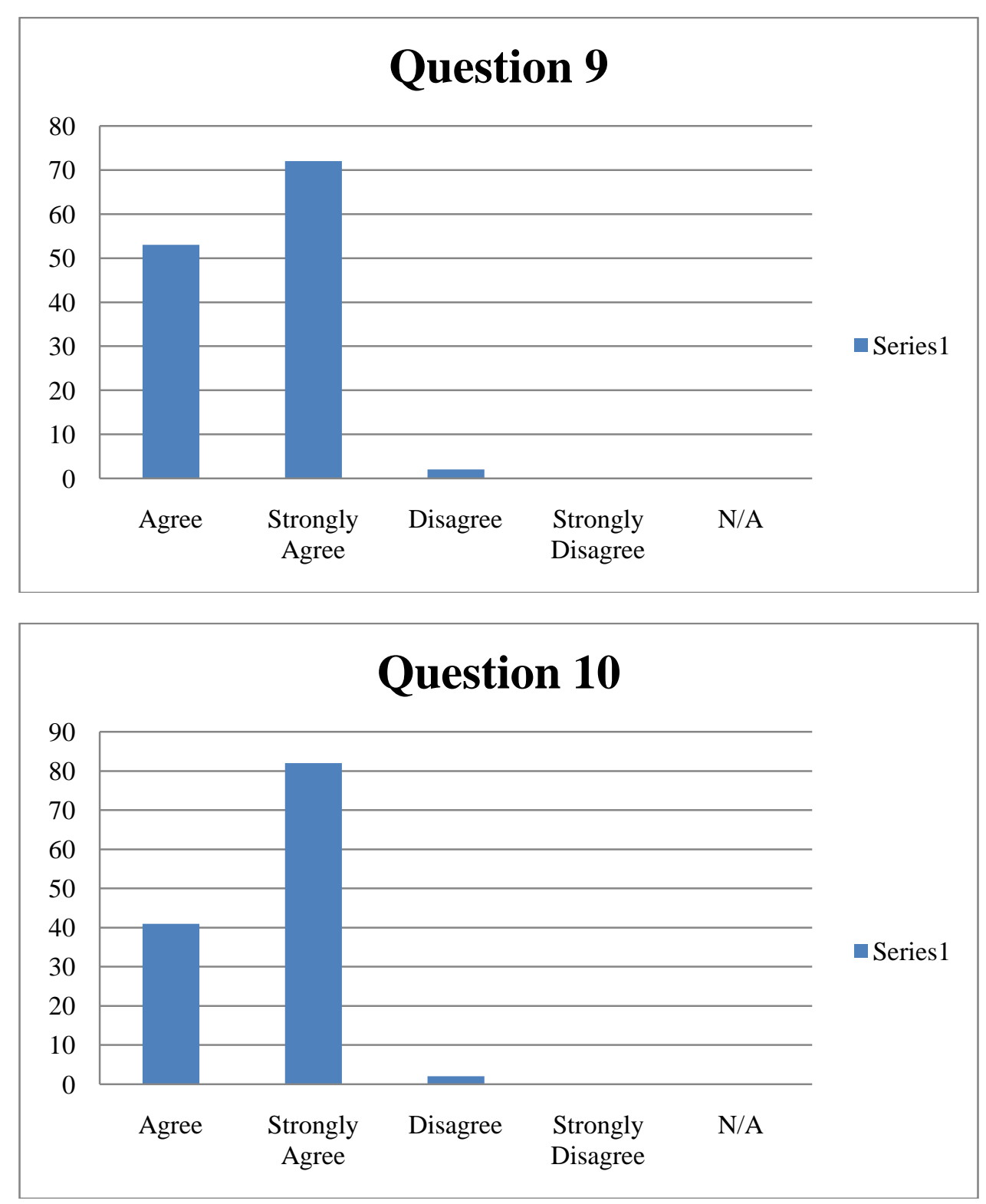

\section{AUTHOR INFORMATION}

Dr. Joseph B. Mosca, Associate Professor of Management in the Leon Hess Business School at Monmouth University earned his doctorate at NYU. Dr. Mosca specializes in Human Resource management, Human Relations, and active teaching methods, and is the recipient of seven teaching awards and three distinguished paper awards. His current research interests focus on developing hybrid courses, employee behavior, and jobs in the $21^{\text {st }}$ Century. E-mail: mosca@monmouth.edu

Dr. Gilda M. Agacer, Associate Professor in Accounting, is currently the interim Associate Dean of the Leon Hess Business School at Monmouth University. Dr. Agacer received her Ph.D. in Accounting from the University of South Carolina. Her teaching interests are in the areas of Management and Cost Accounting. Her research interests include ethics, assurance of learning, and environmental accounting. She has a number of articles published in refereed journals. 
Dr. Linda Flaming, Associate Professor in Accounting, is currently the Interim Chair of the Department of Accounting, Leon Hess Business School, at Monmouth University. Dr. Flaming received her Ph.D. in Accounting from the University of Oklahoma. Her areas of teaching include financial accounting, managerial accounting, and advanced accounting. Her research interests are in the areas of behavioral and decision-making in accounting and ethics.

John S. Buzza is currently a Specialist Professor at Monmouth University and Director of The Monmouth University Center for Entrepreneurship, serving full time since 2005. Education has always been a part of Buzza's life, as he has taught at such schools as Farleigh Dickenson University, Essex County College, The Katherine Gibbs School and guest lectured at many other institutions of higher learning throughout the tri-state area. While at FDU and through 2003, Buzza also served on the Board of The Farleigh Dickenson School of Hotel, Restaurant and Tourism Management. In 2010, the Entrepreneurship course taught by John Buzza received the "Most Innovative Entrepreneurship Course Award" in the country by The United States Association for Small Business and Entrepreneurship (USASBE). Mr. Buzza has served on the Board of The Katherine Gibbs School, working as a liaison between the community and the planned expansion of their campus. Although teaching has always been Mr. Buzza's passion, he has made his mark as an Entrepreneur, being involved as an owner or partner in many different restaurants and catering facilities, two franchise operations and a consulting business. Buzza spends most of his free time involved in many philanthropic endeavors such as Project Pride, an organization that raises money for underprivileged college-bound students in Newark, and Fresh Start, a New York based organization that mentors incarcerated men in the field of Hospitality at Rikers Island Prison. John Buzza received his Bachelors degree from Monmouth College in 1971 and received his Masters Degree from the University of Phoenix in 2003. John is married to Phyllis for 39 years, resides in Jackson New Jersey and has two sons, Matthew and John. E-mail: jbuzza@monmouth.edu

\section{REFERENCES}

1. Barnes, Stephen, (2010). "The Question is the Answer," Teaching Business and Economics, p. 10.

2. Barrie, Simon, Ginns, Paul, Prosser, Michael, (2005). "Early impact and outcomes of an institutionally aligned, student focused learning perspective on teaching quality assurance," Assessment and Evaluation in Higher Education, Volume 30, Number 6, pp. 641-656.

3. Bentley, Paul, (2009). "Developing self-assessment skills in the context of level 3 BTEC business courses," Teaching Business and Economics, pp 30-31.

4. Bloom, B. S. (1956)- "Taxonomy of Educational Objectives, the classification of educational goalsHandbook 1: Cognitive Domain, New York: McKay.

5. Cohen, S. A. (1987). "Instructional Alignment: Searching for a Magic Bullet," Educational Researcher, Volume 16, Number 8, pp16-20.

6. Durden, Guy, (2009). "Assessment Objectives: are they really at the heart of GCSE Business Studies," Teaching Business and Economics, pp16-19.

7. Fairbrother, Jeffrey, Barros, Joao, (2010). "The Effects of Repeated Retention Tests Can Benefit as Well as Degrade Timing Performance," Washington: Research Quarterly for Exercise and Sport, Volume 81, Iss.2, pg. 171, 9 pgs.

8. Gallimore, R., Tharp, R.(1990). "Teaching Mind in Society,” Teaching: Schooling, and Literate Discourse, Cambridge, England: Cambridge University Press.

9. Harmer, Brian, "Teaching in a contextual vacuum: lack of prior workplace knowledge as a barrier to sensemaking in the learning and teaching of business courses," Innovation in Education and Teaching International, Volume 46, Number 1, pp. 41-50.

10. Lavy, Ilana, Yadin, Aharon, (2010). "Team-Based Peer Review as a Form of Formative Assessment-The Case of a Systems Analysis and Design Workshop," West Lafayette: Journal of Information Systems Education, Volume 21, Iss 1, pg 85, 14 pgs.

11. NFER, (2007). "Guidance for Schools," Assessing Enterprise Capability.

12. Ratner, C. (1991). "Vygotsky's Sociohistorical Psychology and its Contemporary Applications," New York: Plenum Press.

13. Ravitch, Diane, (2010). "The Great Accountability Hoax," Learning Newsletter, newsletter@thelearner.com, July 30, 2010. 
14. Vygotsky, L. S. (1986).”Thought and Language,” (A. Kozulim, Trans). Cambridge, Ma: MIT Press.

15. Weiten, Wayne, (2011). "Concepts Charts for Study and Review to Accompany Psychology themes and Variations," Wadsworth Cengage Learning, p15.

16. William, D, and Black, P.,(1998). "Inside the Black Box: Raising Standards through Classroom Assessment," Nfter Nelson.

17. Wilson, Claire, (2010). "Assessment of enterprise capability: some proposals," Teaching Business and Economics, pp 25-26.

\section{NOTES}

